\title{
Seed Size Effects on Early Seedling Growth and Response to Applied Nitrogen in Annual Ryegrass (Lolium multiflorum L.)
}

\author{
Paul W. Bartholomew \\ USDA-ARS Grazinglands Research Laboratory, El Reno, OK, USA \\ Email: paul.bartholomew@ars.usda.gov
}

Received 9 September 2015; accepted 25 October 2015; published 28 October 2015

Copyright (C) 2015 by author and Scientific Research Publishing Inc.

This work is licensed under the Creative Commons Attribution International License (CC BY). http://creativecommons.org/licenses/by/4.0/

(c) (i) Open Access

\begin{abstract}
Use of individual plants as experimental units may be necessary when resources are limited, but inter-plant variation risks obscuring differences among treatments. Experiments were undertaken to measure the effects of seed size on seedling size and response to applied nitrogen of annual ryegrass (Lolium multiflorum L.) harvested six or nine weeks after emergence. In two series of experiments, shoot and root dry weights of seedlings increased respectively at means of 53 - 61 and 29 - 30 mg $\mathrm{mg}^{-1}$ increase in mean seed weight. Between the largest and smallest seed sizes used in this study, there was $83 \%$ difference in shoot weight at harvest six weeks after emergence and $22 \%$ difference with harvest nine weeks after emergence. Nitrogen (N) application, in comparison, increased shoot dry weights by averages of $69 \%$ and $77 \%$ with harvests at six or nine weeks, respectively. Dry mass response to $\mathrm{N}$ application was similar across seed size categories in shoots or roots. A mean $30 \%$ of total seedling- $\mathrm{N}$ was retained in roots. Nitrogen utilization efficiency for shoot growth (increase in shoot growth per unit increase in shoot $N$ capture) ranged from 64 $\mathrm{mg} \cdot \mathrm{mg}^{-1}$ with harvest six weeks after emergence to $114 \mathrm{mg} \cdot \mathrm{mg}^{-1}$ with harvest at nine weeks after emergence. Delay in seedling harvest from six to nine weeks post-emergence and use of closely-graded seed can reduce variation in individual seedling size and contribute to reduction in random variation in small-scale experiments.
\end{abstract}

\section{Keywords}

Seed Size, Seedling Growth, Lolium multiflorum

\section{Introduction}

Limited seed availability or other resource constraints may create a need for small-scale studies using individual 
plants as experimental units to measure plant responses to management inputs. Variability among single plant units may, however, negate the resource-saving benefits of small-scale experimentation if it obscures important differences in response to treatments applied. Among a range of cool-season pasture grasses, seed weight has been shown to be positively correlated with growth rates of seedling shoots and roots [1]-[3]. Some reports have concluded that the effect of seed size on seedling growth is of relatively short duration [1] [4] [5] but others have observed effects sustained between 45 days [6] and 97 days [3] after planting. In field trials with annual ryegrass, increased seed size increased herbage yields at initial harvests taken 8 - 15 weeks after planting [7], although in this instance seed size was confounded with ryegrass cultivar. If a discernible effect of seed size on plant growth persists beyond the early stages of seedling growth, it may present an important source of variability in smallscale experiments that use single plants to test treatment effects. The extent to which this variability may be controlled by improved seed grading is largely unreported. The objectives of the work reported were to evaluate the effects of a range of seed sizes on early season growth of seedlings of annual ryegrass and to determine the effect of seedling size on uptake and utilization of applied nitrogen fertilizer.

\section{Materials \& Methods}

\subsection{Seed Size and Seedling Growth (Series 1)}

A random sample of 600 seeds was taken from a single sack of commercially available annual ryegrass (Lolium multiflorum L.) cv Marshall (The Wax Co., OR). Each seed (meaning caryopsis + lemma + palea) was weighed and a distribution of weights was estimated. Based on this seed weight distribution six seed size categories were established (Table 1) and additional seeds within these size limits were weighed as required for subsequent experiments. Individual seedlings derived from seed from each size category were grown to measure the effects of seed size categories combined with harvest at six or nine weeks after emergence on seedling growth and development. Seedlings were grown in a 50:50 mixture of fine sand and Baccto potting soil [Michigan Peat Co., Houston, TX] containing $840 \mathrm{~g} \cdot \mathrm{kg}^{-1}$ reed sedge peat $+160 \mathrm{~g} \cdot \mathrm{kg}^{-1}$ sand and perlite, packed into $655 \mathrm{~mL}$ D40H Deepots (Stuewe \& Co., OR). Two seeds were sown in each pot, covered to a depth of $5 \mathrm{~mm}$ with growing medium. Within three days after emergence seedlings were thinned as necessary to a single plant in each pot and were fertilized with a commercial complete nutrient solution at a rate equivalent to application of $50 \mathrm{~kg} \cdot \mathrm{N} \cdot \mathrm{ha}$. Pots were watered at a frequency sufficient to maintain soil moisture above $20 \%$ volumetric water content. Plants were destructively harvested at six or nine weeks after emergence, according to designated treatment, by removal of the entire plant and growing medium from each pot and separating roots from soil by agitation under a stream of water, followed by separation of above-surface biomass (shoot) at the root crown. Counts were made of tiller and emerged leaf numbers on each harvested plant. Root and shoot material was then dried at $60^{\circ} \mathrm{C}$ for measurement of component DM yield. Each treatment was replicated ten times and the experiment was repeated three times. All experiments were carried out in a greenhouse, experiment 1 under ambient temperatures (no overnight heating) in March and April of 2013, and experiments 2 and 3, with supplementary heating, in November and December of 2013 and January and February 2014. Temperature conditions for all experiments (series 1 and 2) are summarized in Table 2. No artificial lighting was used in any experiment.

\subsection{Seed Size and Nitrogen Application Effects on Seedling Growth (Series 2)}

Cultural procedures identical to those used for investigation of seed size effects on seedling growth were used to

\begin{tabular}{|cc|}
\hline Table 1. Seed weight categories: mean seed weight and weight range. \\
\hline Mean seed weight (mg) & Seed weight range (mg) \\
\hline 1.0 & $0.9-1.1$ \\
1.5 & $1.4-1.6$ \\
2.0 & $1.9-2.1$ \\
2.5 & $2.4-2.6$ \\
3.0 & $2.9-3.1$ \\
3.5 & $3.4-3.6$ \\
\hline
\end{tabular}


Table 2. Temperature conditions at 6 wk (early) and 9 wk (late) harvests for series 1 \& 2 experiments.

\begin{tabular}{cccccc}
\hline \multirow{2}{*}{ Series } & \multirow{2}{*}{ Experiment } & \multicolumn{3}{c}{$\begin{array}{c}\text { Accumulated temperature }{ }^{\circ} \mathrm{C} \\
\text { above } 0{ }^{\circ} \mathrm{C}\end{array}$} & Mean temperature ${ }^{\circ} \mathrm{C}$ Daily temperature range ${ }^{\circ} \mathrm{C}$ \\
\cline { 2 - 4 } & & 6 wk & 9 wk & & \\
\hline \multirow{3}{*}{1} & 721 & 1091 & 17.3 & 24.3 \\
& 2 & 1133 & 1518 & 21.4 & 16.3 \\
& 3 & 737 & 1080 & 17.4 & 11.7 \\
& & & & & 13.6 \\
& 1 & 757 & 1137 & 17.8 & 13.6 \\
& 2 & 764 & 1155 & 18.0 & 12.8 \\
& 3 & 782 & 1196 & 18.7 & 14.2 \\
\hline
\end{tabular}

investigate the combined effects of nitrogen application and seed size on seedling growth, uptake and utilization of nitrogen. Three seed size category treatments $(1.25,2.25$ or $3.25 \mathrm{mg}$ mean seed weight within ranges of 0.9 1.6, 1.9 - 2.6 or 2.9 - $3.6 \mathrm{mg}$, respectively) were combined with harvests at 6 or 9 weeks post emergence and with or without application of the equivalent of $50 \mathrm{~kg} \cdot \mathrm{N} \cdot \mathrm{ha}$, applied in the form of ammonium nitrate in aqueous solution (0.0575 molar). Each treatment combination was replicated in five plants and the experiment was repeated four times in the greenhouse, February - August 2014, with overnight heating and daytime cooling to control diurnal temperature variation. A 15-seed sample from each size category was dissected to estimate caryopsis weight as a proportion of total seed weight. After harvest, dried root and shoot components were ground using a Retsch ball mill (Retsch Gmbh, 5657 Haan, Germany). The ground material from five replicate plants was combined into a single sample for each treatment and analyzed for total $\mathrm{N}$ content, to estimate $\mathrm{N}$ uptake and distribution through the plant.

\subsection{Statistical Procedures}

In each experiment, individual replicate plant data were combined to provide a single treatment mean for each parameter. Results were analyzed by ANOVA [8] with seed size, harvest date and nitrogen treatment (as appropriate) as fixed effects and repeated experiments as random effects, representing three replications for series 1 and four replications for series 2. Genstat regression procedures were used to estimate seedling growth and nitrogen uptake responses to seed size, harvest stage and nitrogen application treatments.

\section{Results}

\subsection{Seedling Characteristics Affected by Seed Size (Series 1)}

Number of leaves or tillers per seedling was not significantly affected by size of seed planted. Seedling mean leaf numbers were 15.0 and 25.6 at six and nine wk harvests, respectively. Mean tiller numbers increased from 5.1 at six wk to 7.4 at nine wk. Delaying harvest from six to nine weeks after emergence increased mean dry seedling size from 332 to $973 \mathrm{mg}$. Seedling total and component biomass was significantly increased by increase in size of planted seed. A linear relation of seed weight and seedling dry weight explained $79 \%$ of variation in seedling size. Dry shoot weight increased at $53.0 \mathrm{mg} \cdot \mathrm{mg}^{-1}$ increase in sown seed weight and the rate was similar at harvests six or nine weeks after emergence (Figure 1(a)). Over the range of seed sizes used in this study there was up to $83 \%$ difference in shoot weight at harvest six weeks after emergence and $22 \%$ difference with harvest nine weeks after emergence. Dry root mass also showed a linear relation with seed size, increasing at 30.1 $\mathrm{mg} \cdot \mathrm{mg}^{-1}$ increase in mean seed weight (Figure $1(\mathrm{~b})$ ). The effect of seed size on shoot: root ratio was not significant $(\mathrm{P}<0.05)$.

\subsection{Seed Size and Applied N Effects on Seedling Size (Series 2)}

Nitrogen application and increased seed size increased dry shoot and root weights (Figure 2(a) and Figure 2(b)). 


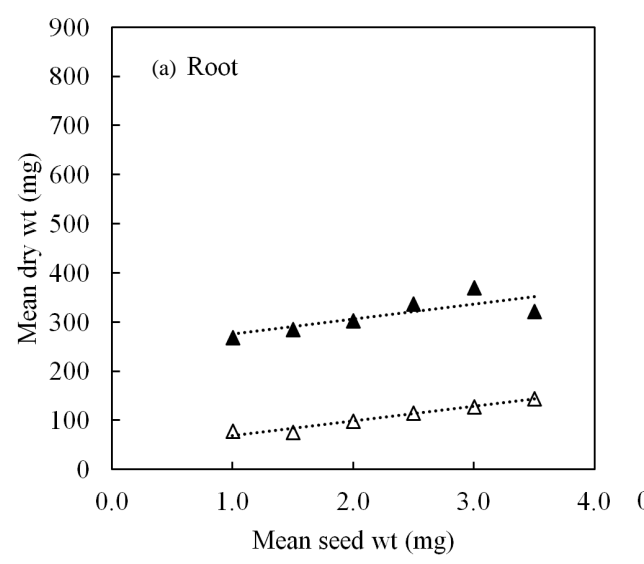

$\Delta 6 \mathrm{wk} \Delta 9 \mathrm{wk}$

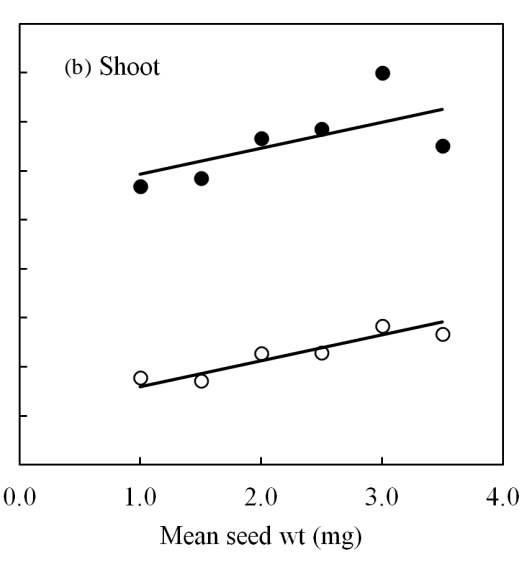

06 wk $\bullet$ wk

Figure 1. Effects of seed weight and harvest at 6 or 9 weeks post-emergence on (a) root and (b) shoot yields of seedlings of annual ryegrass (Lolium multiflorum L.) cv Marshall. Equations: (a) Root dry wt $(\mathrm{mg})$ at $6 \mathrm{wk}=30.1 \times$ seed wt $(\mathrm{mg})+38.4$; root dry wt $(\mathrm{mg})$ at $9 \mathrm{wk}=30.1 \times$ seed wt (mg) + 245.9; (b) Shoot dry wt (mg) at 6 wk = $53.0 \times$ seed wt (mg) + 106.4; shoot dry wt (mg) at $9 \mathrm{wk}=53.0 \times$ seed $\mathrm{wt}(\mathrm{mg})+540.0$.

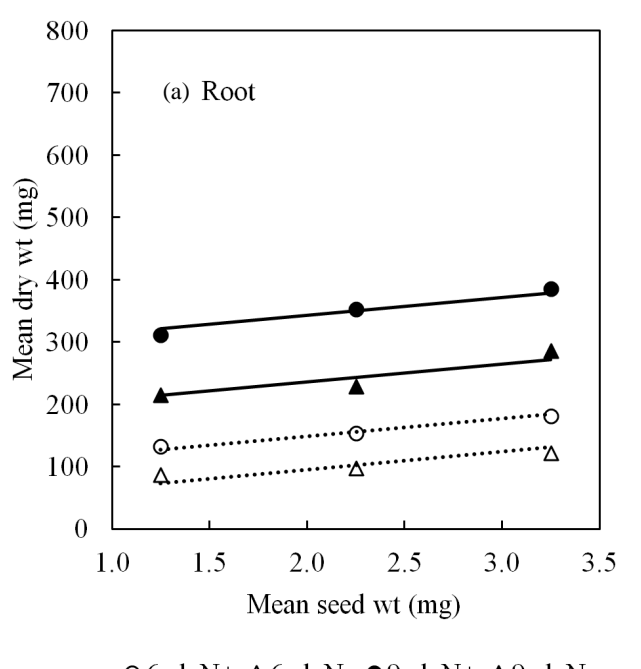

$06 w k N+\Delta 6 w k N-\bullet 9 w k N+\Delta 9 w k N-$

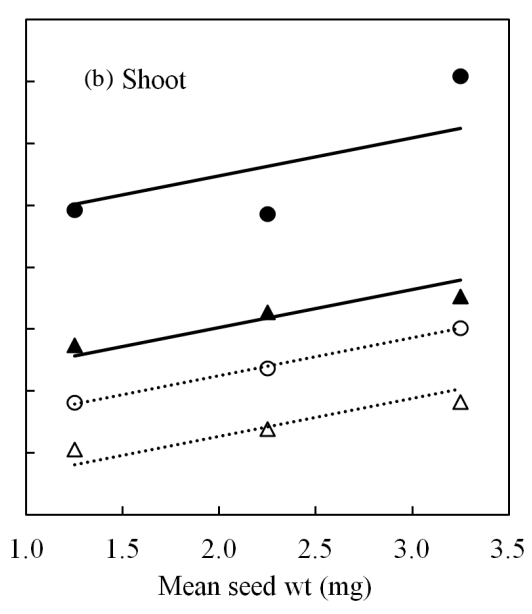

$06 w k N+\Delta 6 w k N-\bullet 9 w k N+\Delta 9 w k N-$

Figure 2. Effects of nitrogen application, harvest at 6 or 9 weeks after emergence and seed size on shoot and root yields of seedlings of annual ryegrass (Lolium multiflorum L.) cv Marshall. Equations: (a) Root dry wt (mg) 6 wk N+ = $28.6 \times$ seed wt (mg) +91.2; Root dry wt (mg) at 9 wk $\mathrm{N}+=28.6 \times$ seed wt $(\mathrm{mg})+285.4$; Root dry wt $(\mathrm{mg}) 6 \mathrm{wk} \mathrm{N}-=28.6 \times$ seed wt $(\mathrm{mg})+37.9$; root dry wt (mg) at $9 \mathrm{wk} \mathrm{N}-=28.6 \times$ seed wt $(\mathrm{mg})+178.5$. (b) Shoot dry wt (mg) at 6 wk N+ $=61.2 \times$ seed wt (mg) + 102.9; shoot dry wt (mg) at 9 wk $\mathrm{N}+=61.2 \times$ seed wt $(\mathrm{mg})+425.1$; shoot dry wt $(\mathrm{mg})$ at $6 \mathrm{wk} \mathrm{N}-=61.2 \times$ seed wt $(\mathrm{mg})+4.8$; shoot dry wt $(\mathrm{mg})$ at $9 \mathrm{wk} \mathrm{N}-=61.2 \times$ seed wt $(\mathrm{mg})+180.7$.

Shoot and root dry weight responses to seed size were similar to those observed in series $1\left(61.2 \mathrm{mg} \cdot \mathrm{mg}^{-1}\right.$ and $28.6 \mathrm{mg} \cdot \mathrm{mg}^{-1}$ for shoot and root, respectively, but there was no evidence of different response to nitrogen according to seed size $(\mathrm{P}<0.05)$. Caryopsis in small medium and large seeds was $77 \%$, $82 \%$ and $78 \%$, respectively, of total seed weight.

\subsection{Nitrogen Capture by Seedlings}

Increased seed size, delayed harvest and $\mathrm{N}$ application all increased $\mathrm{N}$ capture by seedlings (Table 3) but there 
Table 3. Effects of seed size, length of growing period (weeks after emergence) and application of $\mathrm{N}$ on $\mathrm{N}$ capture by seedlings of annual ryegrass.

\begin{tabular}{|c|c|c|c|c|c|c|c|c|c|c|}
\hline & \multicolumn{3}{|c|}{ Seed size } & \multirow{3}{*}{$\begin{array}{c}\text { LSD } \\
(\mathrm{P}=0.05)\end{array}$} & \multicolumn{2}{|c|}{ Growth period } & \multirow{3}{*}{$\begin{array}{c}\text { LSD } \\
(\mathrm{P}=0.05)\end{array}$} & \multicolumn{2}{|c|}{$\mathrm{N}$ application } & \multirow{3}{*}{$\begin{array}{c}\text { LSD } \\
(\mathrm{P}=0.05)\end{array}$} \\
\hline & Small & Medium & Large & & $6 \mathrm{wk}$ & 9 wk & & $\mathrm{N}^{-}$ & $\mathrm{N}+$ & \\
\hline & \multicolumn{3}{|c|}{ N (mg) } & & \multicolumn{2}{|c|}{$\mathrm{N}(\mathrm{mg})$} & & \multicolumn{2}{|c|}{$\mathrm{N}$ (mg) } & \\
\hline Root & 1.28 & 1.40 & 1.60 & NS & 0.99 & 1.86 & 0.22 & 1.19 & 1.67 & 0.22 \\
\hline Shoot & 2.94 & 3.14 & 3.93 & 0.76 & 2.70 & 3.97 & 0.62 & 2.55 & 4.13 & 0.62 \\
\hline Total & 4.23 & 4.53 & 5.53 & 0.97 & 3.69 & 5.83 & 0.79 & 3.73 & 5.80 & 0.79 \\
\hline
\end{tabular}

was no significant interaction among treatment in their effects on $\mathrm{N}$ uptake. Marginal uptake of applied $\mathrm{N}$ was low with a total seedling mean of $13 \%$ of $\mathrm{N}$ applied. The amount of $\mathrm{N}$ harvested in roots was not significantly different among seed size categories but was closely related to root mass, and this relation was not affected by length of growing period or by application of additional $\mathrm{N}$. The distribution of harvested $\mathrm{N}$ between root and shoot was not affected by seed size or by application of $\mathrm{N}$. The proportion of harvested $\mathrm{N}$ present in roots was, however, slightly increased (to 33\% of total) after a nine-wk growth compared with a six-wk growth (28\% of total seedling $\mathrm{N}$ ). Root and shoot DM harvested per unit $\mathrm{N}$ captured ( $\mathrm{N}$ utilization efficiency) was increased by delay in harvest from six weeks to nine weeks after emergence (Figure 3). Nitrogen application and seed size had no significant $(\mathrm{P}>0.05)$ effect on root or shoot $\mathrm{N}$ utilization efficiency.

\section{Discussion}

Effects of seed size on seedling size reflect results in other published work with cool-season grasses [1] [5] [6] but were generally more sustained (to at least nine weeks post-emergence) than in these earlier reports. Caryopsis as a proportion of total seed weight showed no trend with seed size and presented an overall average of $79 \%$ that was comparable with other published values [9]. Grading seed to a narrower range of sizes than in a commercially available sample can substantially reduce variability in growth among seedlings. Remaining inter-plant variability can be still further reduced by delay in harvest, at least up to nine weeks post-emergence.

Here, the mean effect of $\mathrm{N}$ application was a $77 \%$ increase in shoot DM at nine weeks, compared with no $\mathrm{N}$ application. For comparison, at nine weeks after emergence, large seed resulted in a mean $42 \%$ increase in harvested DM, compared with seedlings grown from small seed. Failure to control for seed size variability could readily obscure the effects of other factors affecting seedling size. Plant capture of applied $\mathrm{N}$ by annual ryegrass was quite low (13\% of $\mathrm{N}$ applied) but was within the range reported for perennial ryegrass (Lolium perenne $\mathrm{L}$.) [10] which may reflect a relatively short growing period and a less than fully-developed root system. Although total capture of $\mathrm{N}$ applied was low, its utilization, expressed as increase in shoot growth per unit increase in $\mathrm{N}$ in shoot, equivalent to leaf nitrogen use efficiency [LNUE] [11], ranged from 64.0 to $113.9 \mathrm{mg} \cdot \mathrm{mg}^{-1}$, greater than some values reported for perennial ryegrass [12], but within the range of LNUE after 8 weeks growth reported by other authors [13], also with perennial ryegrass. The proportion of total seedling $\mathrm{N}$ retained in roots averaged $30 \%$ and closely matched values reported by Crush et al. [14]. The use of individual plants as experimental units was driven by an anticipated need to make best use of limited supplies of seed while limiting random variation. Results show that seed grading offers some control of inter-plant variability, but the grading process is labor intensive. Other observations (Bartholomew, unpubl.) have shown that multiple seedlings (three rather than singles) can provide a similar degree of experimental precision to that provided by single plants grown from weight-graded seed. Sowing multiple (random) seeds might eliminate the grading process but it would require a greater supply of seeds, which is counter-productive to the desire to minimize seed use. Since there was no significant interaction of seed weight and harvest date or $\mathrm{N}$ application treatments, different grades of seed could be used as replication, thereby maximizing available seed while minimizing interplant variability.

\section{Acknowledgements}

The author gratefully acknowledges the valuable technical support of Ms Kathie Wynn and Mr Justin Cash in execution of this research. The work was funded by the US Department of Agriculture-Agricultural Research 


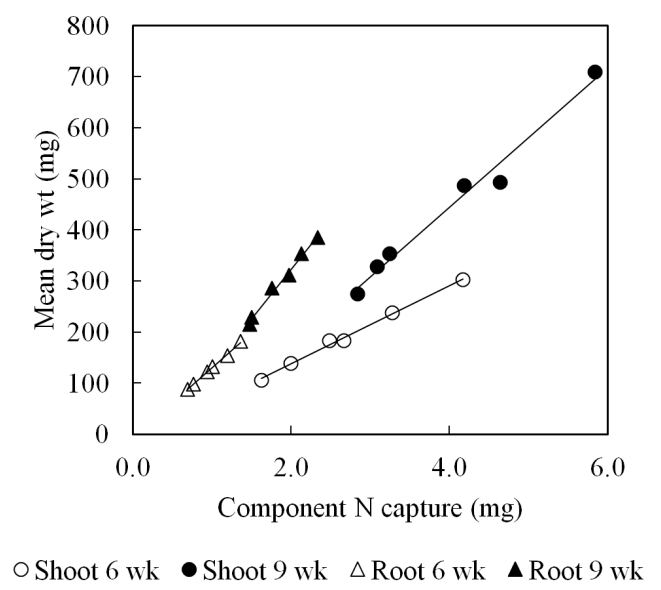

\begin{abstract}
Figure 3. Seedling root and shoot production of annual ryegrass (Lolium multiflorum L.) cv Marshall at harvests 6 or 9 weeks after emergence in relation to nitrogen uptake by each component. Equations: (a) Root DM (6 $w k)=129.3 \times$ Root N + 0.9; Root DM (9 wk) $=168.0 \times$ Root $N-16.3$. (b) Shoot DM $(6 \mathrm{wk})=64.0 \times$ Shoot $\mathrm{N}+18.7$; Shoot DM $(9 \mathrm{wk})=113.9 \times$ Shoot $\mathrm{N}-11.7$.
\end{abstract}

Service (USDA-ARS). Mention of trademark names does not represent an endorsement over comparable products by the USDA-ARS.

\title{
References
}

[1] Harkess, R.D. (1965) The Effect of Seed Size on Early Growth of Diploid and Tetraploid Italian Ryegrass. Journal of the British Grassland Society, 20, 190-193. http://dx.doi.org/10.1111/j.1365-2494.1965.tb00421.x

[2] Arnott, R.A. (1969) The Effect of Seed Weight and Depth of Sowing on the Emergence and Early Seedling Growth of Perennial Ryegrass (Lolium perenne). Journal of the British Grassland Society, 24, 104-110. http://dx.doi.org/10.1111/j.1365-2494.1969.tb01053.x

[3] Lewis, E.J. and Garcia, J.A. (1979) The Effect of Seed Weight and Coleoptile Tiller Development on Seedling Vigour in Tall Fescue, Festuca arundinacea Schreb. Euphytica, 28, 393-402. http://dx.doi.org/10.1007/BF00056597

[4] Evans, P.S. (1973) Effect of Seed Size and Defoliation at Three Development Stages on Root and Shoot Growth of Seedlings of Some Common Pasture Species. New Zealand Journal of Agricultural Research, 16, 389-394. http://dx.doi.org/10.1080/00288233.1973.10421121

[5] Venuto, B.C., Redfearn, D.D., Pitman, W.D. and Alison, M.W. (2002) Seed Variation among Annual Ryegrass Cultivars in South-Eastern USA and the Relationship with Seedling Vigour and Forage Production. Grass and Forage Science, 57, 305-311. http://dx.doi.org/10.1046/j.1365-2494.2002.00328.x

[6] Sanderson, M.A. and Elwinger, G.F. (2004) Emergence and Seedling Structure of Temperate Grasses at Different Planting Depths. Agronomy Journal, 96, 685-691. http://dx.doi.org/10.2134/agronj2004.0685

[7] Venuto, B.C., Redfearn, D.D., Pitman, W.D. and Alison, M.W. (2004) Impact of Seeding Rate on Annual Ryegrass Performance. Grass and Forage Science, 59, 8-14. http://dx.doi.org/10.1111/j.1365-2494.2004.00397.x

[8] Genstat (2008) Genstat for Windows, Release 11.1.0.1575. 11th Edition, VSN International Ltd., Oxford.

[9] Hayes, P. (1976) Seedling Growth of Four Grasses. Journal of the British Grassland Society, 31, 59-64. http://dx.doi.org/10.1111/j.1365-2494.1976.tb01118.x

[10] Crush, J.R., Easton, H.S., Waller, J.E., Hume, D.E. and Faville, M.J. (2007) Genotypic Variation in Patterns of Root Distribution, Nitrate Interception and Response to Moisture Stress of a Perennial Ryegrass (Lolium perenne L.) Mapping Population. Grass and Forage Science, 62, 265-273. http://dx.doi.org/10.1111/j.1365-2494.2007.00583.x

[11] Hirose, T. (2012) Leaf-Level Nitrogen Use Efficiency: Definition and Importance. Oecologia, 169, 591-597. http://dx.doi.org/10.1007/s00442-011-2223-6

[12] Legay, N., Personeni, E., Slezack-Deschaumes, S., Piutti, S. and Cliquet, J.-B. (2014) Grassland Species Show Similar Strategies for Sulphur and Nitrogen Acquisition. Plant and Soil, 375, 113-126.

http://dx.doi.org/10.1007/s11104-013-1949-9 
[13] Vasquez de Aldana, B.R. and Berendse, F. (1997) Nitrogen-Use Efficiency in Six Perennial Grasses from Contrasting Habitats. Functional Ecology, 11, 619-626. http://dx.doi.org/10.1046/j.1365-2435.1997.00137.x

[14] Crush, J.R., Waller, J.E. and Care, D.A. (2005) Root Distribution and Nitrate Interception in Eleven Temperate Forage Grasses. Grass and Forage Science, 60, 385-392. http://dx.doi.org/10.1111/j.1365-2494.2005.00488.x 